\title{
The Whys and Hows of Fourth-Year Inflammatory Bowel Disease Fellowships
}

\author{
Robert Hirten $^{1}$ Bruce E. Sands ${ }^{1} \cdot$ Benjamin L. Cohen ${ }^{1}$
}

Published online: 1 April 2017

(C) Springer Science+Business Media New York 2017

I began gastroenterology fellowship without a clear preference for the myriad number of available career options. Many fellows often struggle with the question of whether to pursue a career in academic medicine or in private practice, as well as whether to subspecialize with an additional year of training. The type of gastroenterologist one ultimately becomes depends upon how one responds to these choices. Early in my training, it became clear that I wanted to pursue a career in academic medicine, and by the end of my first year of fellowship I found myself accumulating clinic patients with Crohn's disease (CD) and ulcerative colitis (UC), answering the question of what I should do with my career. While I was relieved by the realization that I wanted to make inflammatory bowel disease (IBD) my calling, it dawned on me that the hard part was how to realize this vision.

The complexity of managing IBD has increased as the number of treatment options expands and as therapeutic drug monitoring and "treat to target" strategies become incorporated into standard practice. While even experienced gastroenterologists have difficulty treating these diseases, it can be particularly challenging as a fellow or junior attending. Competence in managing IBD represents

Robert Hirten

robert.hirten@mountsinai.org

Bruce E. Sands

bruce.sands@mssm.edu

Benjamin L. Cohen

benjamin.cohen@mssm.edu

1 The Dr. Henry D. Janowitz Division of Gastroenterology, Icahn School of Medicine at The Mount Sinai Hospital, 1468 Madison Avenue, Box 1069, New York, NY 10029-6574, USA only a small part of the Gastroenterology Core Curriculum [1]. Differences in clinical experiences create disparities among fellowships with regard to the quality of IBD education, with less than half of fellows feeling comfortable with many aspects of IBD care and only $28 \%$ being satisfied with their level of exposure [2-4]. Like many fellows, I felt that although general training provided a breadth of knowledge enabling me to handle many of the challenges of clinical practice, additional education was needed to be comfortable with the intricacies inherent in the management of IBD.

The nature of additional training depends upon the type of career within IBD one chooses to pursue. Those considering such a career should first discuss their goals with their mentors or program directors in order to determine the path that best fits with their interests and background. One option is The Visiting IBD Fellow program sponsored by the Crohn's and Colitis Foundation (CCF). This intensified IBD educational experience, available during the second or third year of fellowship, is a one month elective sited at a leading IBD center that provides exposure to evidence- and opinion-based approaches by expert faculty practicing in high-volume programs [5]. For many, this experience, adequate for added comfort in managing complicated disease, provides a wonderful opportunity to build relationships with mentors from other centers. Another option is the CCF Rising Educators Academics and Clinicians Helping IBD (REACH-IBD), the junior faculty and fellow membership arm of the CCF focused on networking, career development, education, and collaborative research. Moreover, the IBD Xcel program targets junior attending physicians within 5 years of completion of training for two-day workshops with IBD experts aimed at honing their clinical skills [6]. All of these programs may also provide a preview of what is entailed by advanced training with the 
aim of helping young clinicians determine whether such training is something right for them.

During gastroenterology fellowship, I participated in the Visiting CCF IBD Fellowship at The Mount Sinai Hospital, where I later became the Advanced IBD Fellow. Treating complex patients with IBD was among my most personally and intellectually rewarding clinical experiences. After becoming aware of the available clinical and research opportunities during that month, I knew I wanted to focus my career on complex referral patients and the clinical research that takes place at such referral centers. The next step was to determine how to achieve this goal. While additional years of training in transplant hepatology and biliary tract diseases are common ways to specialize, an additional year of training in IBD is something of which many are less aware, despite the enormous benefits that can accrue from such sub-specialized education. Over the past 25 years, advanced fellowships in IBD have emerged to provide the tools needed to master the growing intricacy of patient management intrinsic to this field. Currently, there are 20 fellowships in North America, offering 1-2 positions for 1-2 years, often after completion of gastroenterology fellowship [7].

Advanced IBD fellowship programs provide an unparalleled exposure to tertiary referral-based IBD, building familiarity with the medical and surgical management of refractory disease and developing the endoscopic skills needed to treat these conditions. With IBD care moving toward the medical home model, advanced fellows are exposed to and learn from the multifaceted structure of these centers where IBD experts collaborate closely with experienced pathologists, surgeons, radiologists, dieticians, and clinical research coordinators clinically and in multidisciplinary conferences on a regular basis [8]. Exposure and access to multiple clinical trials and the research offered at IBD centers allows one to participate and develop studies at the forefront of the field and to develop as a physician-scientist. Supplementing these many benefits are mentorship opportunities by leaders in the field providing career advice, clinical and research guidance, and lifelong collaborative friendships.

These IBD fellowships are not accredited by The Accreditation Council for Graduate Medical Education (ACGME); furthermore, a separate certification examination is not offered by the American Board of Internal Medicine (ABIM). The application process is not uniform and may commence 1-2 years prior to the start date of the fellowship depending on the program. Unlike biliary fellowship, this is an informal process that does not use the Electronic Residency Application Service (ERAS). While I was thinking about applying and searching for programs in which I was interested, I spoke with mentors and visited the CCF Web site, which lists IBD fellowships and their contact information (http://www.crohnscolitisfoundation. org/science-and-professionals/programs-materials/visitingibd-fellow-program/advanced-practice.pdf). Additional lists of programs and their contact information are available in journal articles on the subject of advanced IBD training [7]. Given the informal application process, it is recommended that you contact these programs early in order to inquire about their requirements. Generally, an introductory email to the coordinator or fellowship program director formatted as a cover letter with your curriculum vitae attached is sufficient to start the process. Although the competitiveness of these programs varies by institution and by year, strong candidates uniformly demonstrate a clear interest in academic gastroenterology and in IBD.

When choosing a program, you should ensure that the program's strengths align with your career goals since strengths and weaknesses vary by institution. While there is no standardized national curriculum, you should assure yourself that the program to which you are applying has: a high patient volume, ample clinical and research mentorship, the opportunity to rotate with other subspecialties involved in the care of IBD patients, and has multidisciplinary didactics and a formal curriculum. Given the art of managing IBD, the opportunity to work with multiple expert faculty is key, as the practical educational value of learning different management styles cannot be overstated.

While multiple avenues are available to gain a deeper understanding of complex IBD, an advanced IBD fellowship will allow you to improve the quality of your IBD patient care, grow as a researcher, and learn about the workings of a multidisciplinary center. Both academic medical centers and private practices value the skills developed during these fellowships and most importantly so will your patients. Nearing the end of my fellowship at Mount Sinai, I can confidently say that it has been the most rewarding experience of my professional career and that I would highly recommend it based on the opportunities it provides.

\section{Compliance with ethical standards}

Conflicts of interest The authors disclose that they have no conflicts of interest.

\section{References}

1. The gastroenterology core curriculum. 3rd ed. Gastroenterology. 2007;132:2012-2018.

2. Ananthakrishnan AN, Kwon J, Raffals L, et al. Variation in treatment of patients with inflammatory bowel diseases at major US referral centers. Clin Gastroenterol Hepatol. 2015;13:1197-1200.

3. Weizman AV, Nguyen GC. Quality of care delivered to hospitalized inflammatory bowel disease patients. World J Gastroenterol. 2013;19:6360-6366. 
4. Cohen BL, Ha C, Ananthakrishnan A, et al. State of adult trainee inflammatory bowel disease education in the united states: a national survey. Inflamm Bowel Dis. 2016;22:1609-1615.

5. CCFA Visiting IBD Fellow Program. http://www.ccfa.org/scienceand-professionals/programs-materials/visiting-ibd-fellow-program. 2016. Accessed December 10, 2016.

6. Cornerstones Health Inc. Cornerstones IBD XCEL. http://www. cornerstoneshealth.org/\#home-page. 2016. Accessed December 10, 2016.
7. Rubin DT. The rationale and growth of advanced training in inflammatory bowel disease. Gastroenterology. 2015;148:696-700.

8. Regueiro MD, McAnallen SE, Greer JB, et al. The inflammatory bowel disease specialty medical home: a new model of patientcentered care. Inflamm Bowel Dis. 2016;22:1971-1980. 